The effect of using synthetic multisensory phonics in teaching literacy on EFL young learners' literacy learning

Farokhbakht, Leila $\Sigma$

Faculty of Foreign Languages, University of Isfahan, Iran (leilafarokhbakht@gmail.com)

Nejadansari, Dariush

Faculty of Foreign Languages, University of Isfahan, Iran (nejadansari@gmail.com)

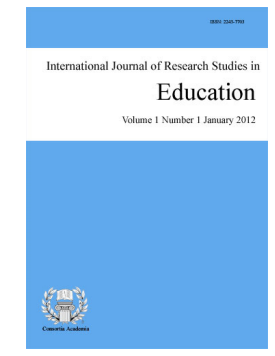

ISSN: 2243-7703 Online ISSN: 2243-7711

Received: 20 April 2015

Revised: 18 May 2015 DOI: $10.5861 /$ ijrse.2015.1196

Accepted: 26 May 2015

OPEN ACCESS

\title{
Abstract
}

The present study sought to investigate the effect of adopting synthetic multisensory phonics (i.e. Jolly Phonics) for teaching early English literacy skills on literacy learning of Iranian EFL young learners. To this end, 100 zero-beginners of English aged between 10 to 12 participated in this study. The participants were randomly assigned to either experimental or control classes. While the students in the control group were taught basic English literacy skills through the rote traditional phonics, the learners in the experimental group were taught English literacy via a synthetic multisensory phonics approach named Jolly Phonics. After a one-month English course, all the participants took a reading and a spelling test. A set of descriptive and inferential statistics were used to analyse students' scores obtained from these tests. The results demonstrated that the experimental (Jolly Phonics) group had a better performance on the reading and spelling tests.

Keywords: phonics; multisensory approach; synthetic phonics; Jolly Phonics (JP); EFL young learners, literacy 


\section{The effect of using synthetic multisensory phonics in teaching literacy on EFL young learners' literacy learning}

\section{Introduction}

Learning to read and write is among the most important skills required for a child's academic success at school as well as in his/her future education. Learning literacy skills will influence one's performances in other disciplines. Literacy can have substantial impacts on developing livelihood. As claimed in a report by The World Bank (2002), people who had fulfilled literacy courses were shown to be more enthusiastic to improve their livelihoods. In addition to that, Eldred (2008) mentioned that literacy is associated with specific job skills as well as developments in critical thinking and problem solving.

Over the years, there's been a tremendous body of research conducted on the factors that affect literacy learning and development (Pretorius \& Mampuru, 2007). However, while researchers have come to an agreement about the different linguistic, socioeconomic, sociocultural and developmental elements in various contexts such as home, school and classroom which directly or indirectly influence the language and literacy achievements, a considerable debate about the best ways of teaching literacy to children continues to exist in the English-speaking countries (Harrison, 2004). In the past, as Chall (1983) put it, at the centre of this great debate was the disagreement among those researchers, educators and policy makers who emphasized the bottom-up approaches (i.e. phonics) to literacy which focused on breaking the code and those who placed emphasis on whole-language (i.e. top-down) approaches in which meaning-emphasis was the centre of attention.

In recent years, however, with the growth of convincing evidence from cognitive science which displays a strong relationship between success in literacy, phonemic/phonological awareness, and phonological skills (Anderson, 2004; Goswami \& Bryant, 1990) and with the educational ministries of English-speaking countries seeking verification from 'scientifically' based research (Schemo, 2002), phonics has been adhered to as the best method of teaching literacy especially in primary stages.

The great debate, also referred to as the 'reading wars' (Burkard, 1999) has now shifted from the debate among the proponents of whole-language approaches and phonics to a disputation over what kind of phonics instruction must be adopted in teaching literacy. According to Burkard (1999),

There is little doubt that proponents of phonics have won the reading war. Almost overnight, the politics of reading changed. Whole-language texts started gathering dust in university libraries.

Phonics was back in fashion. The issue was now finding the best way to teach it (p. 7).

Due to the increasing impact of the governments and curriculum designers of English-speaking countries on selecting phonics as the literacy instruction [e.g. in US and UK (Gregory, 2008; Harrison, 2004) and in Australia and New Zealand (Bowey, 2006)], phonics has also attracted attention in non-native contexts as part of the literacy instruction all over the world (Kuo, 2011). However, unlike the wide range of research supporting the efficacy of phonics instruction especially the successfulness of synthetic and multisensory approaches to phonics (Bowey, 2006; Donnell, 2007; Gaskins, Downer, Anderson, Cunningham, Gaskins \& Schommer, 1988; Grant, 1998; Johnston \& Watson, 2005; Mohler, 2002; Salfer, 2006; Sumbler \& Willows, 1996; Trezek, Wang, Woods, Gampp \& Paul 2007), there is a paucity of research in validation of different methods of phonics in L2 non-English environments specifically in EFL contexts. This gap in the literature raises the question of whether phonics, and specially the synthetic multisensory phonics instruction reveals equal effects on English literacy learning regardless of the learning context and the learners. 


\section{Literature review}

\subsection{Synthetic Phonics}

Explicit phonics instruction focuses on the direct and systematic teaching of the letter sound knowledge and training of the phonological awareness skills, such as blending and segmentation. In short, the teacher who applies explicit phonics teaching in the classroom first introduces the students to blend the sounds together to read or instruct them to listen for the discrete sounds in a word (Sheu, 2008, p. 18).

A number of empirical research studies in both L1 and L2 contexts have advocated the positive effects of synthetic phonics on children's literacy development. For instance, Shue (2008) investigated the effects of explicit phonics instruction on the phonological awareness (such as the awareness of letter-sound knowledge, blending and segmentation skills) development of 34 second-graders in Taiwan. The treatment lasted for over a semester (approximately 200 minutes) of intensive training using a quasi-experimental design. The findings revealed that the participants' overall phonological awareness skills had improved especially those of the low-achievers. Furthermore, the subjects had greatly improved in the VC blending and the phoneme segmentation tasks.

Moreover, Kodae and Laohawiriyanon (2011) examined the efficacy of intensive explicit phonics instruction on reading and spelling attainment of Thai English language learners with reading difficulties. Forty-one 5-graders in a primary school in Thailand participated in this study. The training was given one hour per day within 8 weeks. A one-group post-test and retention test design was used to collect data. The results suggested that both middle and low-achievers benefited from the programme specifically in relation to word recognition ability.

However, a number of researchers namely; Wyse and Styles (2007), Goswami (2007), and Wyse and Goswami (2008) have questioned indubitable efficiency of synthetic phonics arguing that special features of a language regarding literacy acquisition must be taken into account before selecting a method for teaching literacy. Meanwhile, the data obtained from cross-language studies offer some grounds on why English is a relatively difficult language to learn to read. The first reason is that English syllables are phonologically complex. English does not follow a simple CV syllable structure and this affects children's ease of learning. The second reason is that English writing system is very inconsistent. As a result, some words such as yacht must be learnt as holistic patterns. In order to optimize the teaching of early reading in English, all of these factors should be taken into account. Therefore, the instructional programmes for decoding "visual symbols into sounds" have to be designed based on the empirical evidence obtained from cross-language studies (Goswami, 2007).

As it can be gathered from the assertions in this section, due to the phonological complexity and the irregularity of English orthography, we cannot jump into a firm conclusion that the synthetic phonics instruction will produce incredible results in literacy acquisition the same as what it does in other languages with consistent spelling systems such as Finnish, Italian, Greek, etc. Hence, further research is needed to be conducted in this regard.

\subsection{Multisensory Phonics Instruction}

"Using a multisensory teaching approach means helping a child to learn through more than one of the senses" (Bradford, 2008, p.2). In other words, multisensory instruction has received its name because all the information is presented via sight, sound, and kinesthetic means. According to Cameron (2001, p. 142), "children have to make links from meaning to what they see (printed text), what they hear (the spoken language) and what they produce (written words)" in learning to read and write. In order to facilitate the building and strengthening of all these sorts of mental connections, she recommends teachers to use a range of modes and senses. Cameron believes that early literacy activities can provide various opportunities for children to see, hear, 
Farokhbakht, L., \& Nejadansari, D.

manipulate, touch and feel.

Multisensory phonics has long been regarded as being effective for students with special needs such as the hearing impaired or deaf students, dyslexic children, disabled or poor readers, and underachievers. Since the greatest success for children with reading problems have mostly come from explicit instruction, multisensory instruction has also employed synthetic phonics instruction as one of its major components (Mohler, 2002).

However, much like the special needs students, students who are English language learners may lament a difficult time when it comes to reading and literacy. According to Schneider and Evers (2009), special teaching strategies like multisensory instruction should be adopted for teaching literacy to English language learners since they are at risk of poor learning due to their limited English proficiency.

Schneider and Evers (2009) conducted a study in which they tested the effects of multiple multisensory structured language (MSL) teaching strategies on a number of students who were learning German, Hebrew and English as a second language. According to the researchers, "the MSL strategies are evidence-based and can be applied to any language as well as are supported by a variety of teaching resources to assist instructors in helping English language learners improve their English language skills" (Schneider \& Evers, 2009 as cited in Ureno, 2012, p. 6). The research conducted by Schneider and Evers (2009) indicated that MSL instruction revealed promising results for struggling ELLs.

Learning how to read is the foundation of elementary education in which all young children will either learn with ease, or with difficulty and hesitation. Reading requires the memorization of phonemes, sight words and high frequency words in order to decode texts; and through active experiences, children construct their understanding of the world (Gunning, 2009, as cited in Ureno, 2012, p.2).

Being active learners in the classroom can come from a number techniques and methods such as musical or kinaesthetic approaches to instruction. Using multisensory approaches in reading and literacy instruction has demonstrated to be not only beneficial but also strongly stimulating for learners as well. Therefore, educators can insure an interactive, fun and beneficial alternative to traditional literacy instructions by using multisensory methods for teaching reading. According to Ureno (2012), although there is research that supports these claims, the topic regarding multisensory techniques hasn't been investigated in many ESL/EFL contexts and needs to be further examined by more researchers in more areas of the world.

\subsection{Jolly phonics}

Jolly Phonics is a fun and child-centred approach to teaching literacy which has actions for each of the 42 letter sounds of English and teaches five key skills for reading and writing by using a synthetic multisensory approach. These five skills include (i) learning the letter sounds which consist of the alphabet sounds as well as diagraphs (e.g. sh, ai, etc.), (ii) learning letter formation, (iii) blending, (iv) segmenting, and (v) tricky words that have irregular spellings and children learn them separately in this method ("Teaching Literacy with Jolly Phonics", December 2014). Some of the most recent research studies conducted on the successfulness of the Jolly Phonics method are presented in this below.

Stuart (1999) conducted a study with 112 five-year-old children, 96 of whom were English second language learners. The participants were assigned to either the experimental group (Jolly Phonics intervention) or the control group which used a whole-language approach based on Holdaway's (1979) use of big books. Prior to the 12-week intervention, all the children were pretested on measures of phonological awareness, alphabet knowledge, and spoken and written language. Right after the intervention and again one year later, they were all post-tested on all these measures. The results showed that the Jolly Phonics programme contributed a lot to children's acquisition of phoneme awareness and phonics knowledge as well as their ability to apply this knowledge in reading and writing. 
Johnston and Watson (2005) conducted a longitudinal research study on the beneficial effects of synthetic phonics instruction on literacy attainments of primary school children over 7 years in Clackmannanshire, Scotland. Around 300 children in primary 1 were divided into 3 groups. One group was taught through the synthetic phonics (Jolly Phonics programme), one by the analytic phonics method, and one by an analytic phonics programme plus rhyme and phonemic awareness training. In order to make sure that the improvements in children's literacy learning were maintained, the progress of all these children was followed from primary 1 to primary 7 while their performance in spelling, word reading, and reading comprehension were permanently assessed. It was discovered that at the end of primary 7, the JP group was 3 years 6 months ahead of their chronological age in word reading, 1 year 8 months ahead in spelling and 3.5 months ahead in reading comprehension.

Ekpo, Udosen, Afangideh, Ekukinam, and Ikorok (2007) sought to investigate the relative effects of Jolly Phonics on enhancing primary one students' reading skills. The participants of the study consisted of 168 primary-one pupils from 5 schools in 3 senatorial district of Akwa Ibom State in Nigeria. Two intact classes in each school were selected to form the experimental and control groups. The experimental groups received the Jolly phonics programme as the treatment. The experimental group gained from 3-29 months reading age (5.3 to 5.7) in the Burt Reading Test. Accordingly, the results revealed that JP was effective in enhancing children's reading skills.

In 2011, Dixon, Schhagen and Seedhouse studied the impact of Jolly Phonics intervention on children's English literacy skills in low-income schools in India. This study used a quasi-experimental design in which over 500 students in 20 schools participated in the 6-month programme. While the control group continued with their ordinary English lessons, the experimental group which consisted of over half of the participants experienced lessons organized around the JP materials. The students' scores in reading and spelling tests demonstrated that the intervention groups (JP groups) had significantly improved compared to the control group.

Eshiet (2012) inquired into the possible effects of Jolly phonics on improving the reading skills of Nigerian children. She adopted Jolly phonics as the intervention in a case study design with mixed method approach. The quantitative data was collected through standardized reading and spelling tests while the qualitative data was obtained from focus group discussion of teachers. The findings demonstrated that the JP method let to the improving of pupils' reading achievement as well as an increase in teachers' interest in teaching English.

Shepherd (2013) investigated the effect of Jolly Phonics programme on increasing basic literacy skills of Nigerian primary school students in Cross River State, Nigeria. Almost 300 children, across 6 schools participated in in this 8-month study. At each school, one class received daily lessons using the JP method and one control class continued with the traditional method which mostly consisted of rote learning and memorization. Using the Early Grade Reading Assessment tools, a pretest/posttest comparison was conducted which tested a number of basic literacy skills in English. The results demonstrated that the children in JP groups performed at a much higher level on literacy assessments than those who received their normal literacy instruction.

\subsection{Summary}

As it was elaborately explained in this section, the existence of opposing results about the efficacy of synthetic phonics for teaching English literacy skills reveal the pressing need for further research. Moreover, most of the research in the literature has been carried out in native English-speaking and L2 contexts. Besides, the benefits of multisensory approaches to phonics have mostly been investigated with the deaf or hearing-impaired children or the students with special needs, and mainly in L1 contexts rather than with English language learners or in non-native contexts. The present study is presumed to fill the lacuna in this regard by adopting the Jolly Phonics method which uses a combination of synthetic and multisensory approach to phonics instruction. Consequently, it is expected that the JP programme will turn out to yield promising results in the 
Farokhbakht, L., \& Nejadansari, D.

Iranian EFL context as well.

\section{Methodology}

\subsection{Research questions and hypotheses}

The present study sought to find answer to the following questions:

$>$ Does the synthetic multisensory approach to phonics (i.e. JP instruction) in comparison with traditional approach have any significant effect on Iranian young EFL learners' reading skills?

$>$ Does the synthetic multisensory approach to phonics (i.e. JP instruction) in comparison with traditional approach have any significant effect on Iranian young EFL learners' spelling skills?

Based on the above research questions, the following null hypotheses were formulated:

$>\quad$ The synthetic multisensory approach (JP method) adopted for teaching early literacy does not have any significant effect on the reading skills of Iranian EFL children.

$>\quad$ The synthetic multisensory approach (JP method) adopted for teaching early literacy does not have any significant effect on the spelling skills of Iranian EFL children.

\subsection{Participants}

One hundred participants ranging from 10-12 years old were selected through non-random convenience sampling from among the EFL elementary learners in Sokhansara Language Institute. The reason for selecting these students was that they were going to learn English for the first time. Therefore, the utilization of each of the two phonics instruction methods could be observed in teaching literacy to them. In order to make sure that the students were homogeneous in terms of their oral language and alphabet knowledge in English (i.e. to become sure that all of them were zero beginners of English), the ones that had any familiarity with the alphabets or had studied English before in any other institute or had been home schooled in English were recognized prior to the treatment and excluded from the study. Consequently, the permission of the head of the institute was obtained for implementing the project. Also, parents of the students were informed about the project and their consent was gained.

\subsection{Treatment}

This quasi-experimental study was conducted during an English summer course and lasted for 30 sessions. The learners were assigned to eight Starter classes according to their age and their elementary education levels (zero beginners) by the institute. Each class had an average number of 15 students. As a result, we had four control groups including about 50 students and four experimental groups similarly including about 50 students. The students in the control groups proceeded with their ordinary lessons which were organized around the rote traditional phonics. Their teacher started by teaching the letters of alphabet and their associated sounds followed by teaching some example words that started with those specific alphabet letters (e.g. apple is introduced as an example word for the letter sound $a$ ). This procedure was usually done through repeated drills in which the teacher chanted the words and students repeated after the teacher in unison. However, the teachers who were selected for teaching the experimental classes had been trained in the Jolly Phonics workshop.

The students would attend the English classes 6 days a week. The treatment was carried out in thirty 90-minute sessions. Forty five minutes of each session was devoted to teaching literacy skills through the Jolly Phonics programme and the other 45 minutes was allotted to teaching other language skills and sub skills, i.e. the simple dialogues, songs, structures and vocabulary items in the children's textbook (Hip Hip Hooray Starter). 

order.

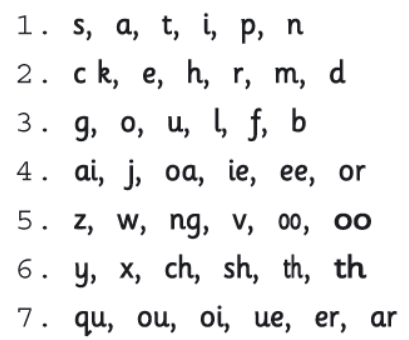

This allows the possibility of forming very simple three-letter words from the very early stages. For example, the words pin, pan, tip, sat could be formed when the first group of sounds is taught.

Each of the above letter sounds were introduced to children via its related action, song and story. Then, the correct way of letter formation was taught with teacher showing the formation on the board. The children would follow the teacher's movement simultaneously showing the letter formation in the air and tracing the dotted letters with their finger in their pupil book or the big finger phonics books. This multisensory approach offers children movement, sight, hearing and speech to help them remember and motivates them to learn literacy skills (Jolly, 2012). After that, the teacher would teach blending and segmenting in order to aid children with reading and writing. Students were taught how to sound out the individual sounds in the words and then mixing them together to read the words.

Furthermore, they learnt to listen carefully for the sounds in words by holding up a finger for each sound and then write the words. The words which have irregular spellings are referred to as tricky words in Jolly phonics method. Since these words couldn't be learnt by blending and segmenting skills, they were taught by practice, repetition and further exposure through different techniques such as word wall posters and mnemonics. These 5 basic literacy skills, namely learning the letter-sounds, letter formation, blending, segmenting and tricky words were all taught and revised using the flash cards, posters, games and other intriguing materials offered and provided by the Jolly Learning Ltd during the course.

\subsection{Instruments}

Since the purpose of the present study was to simply assess learners' phonics knowledge after a particular period of instruction, a one-shot design was used. This design is a common design employed in cross-sectional language studies, where the respondents are recruited on a one-off basis. Therefore, two instruments were utilized to collect the data in this study. Each instrument is discussed below:

The word reading test: A 25-item word reading test was administered to the participants individually to observe the effect of each method of teaching phonics on students' reading skills. In order to estimate the effect of instruction on improving learners' reading proficiency, all the items in this test were unseen.

The spelling test: A 42-item fill in the blank spelling test was given to children in order to estimate the effect of each of the two methods of teaching phonics on improving their spelling skills. Each item represented one of the 42 letter-sounds of the English language. Unlike the word reading test, all the items in the spelling test were seen. They were all selected from the vocabulary items in the students' course book (Hip Hip Hooray Starter).

\subsection{Reliability and validity of the tests}

Using Cronbach's alpha, the internal consistency (reliability) of the word reading test and the spelling test was estimated. The results respectively indicated the reliability index of 0.74 and 0.82 for the word reading test and the spelling test. With regard to validity, both of the tests enjoy content validity by nature because they 
Farokhbakht, L., \& Nejadansari, D.

evaluate the literacy (reading and spelling) skills of the young learners, which is compatible with the objectives of the study. However, a pilot study and experts' judgement were also conducted in order to become more certain about the validity of the tests. Before being administered to the participants, the word reading test and the spelling test were given to several M.A students, Ph.D. students and university teachers of the University of Isfahan in order to be examined, evaluated and edited in terms of content and face validity. The tests were subsequently qualified as being valid by the experts.

After receiving the experts' judgment, the aforementioned researcher-made tests were piloted with a similar group of zero beginners at the same age who were not the target participants of the study. Issues regarding the administration, the required time, clarity of the tests as well as their rubric were inspected in this pilot study.

\subsection{Scoring procedures}

In scoring the word reading test and the spelling test, every item was graded dichotomously: one point for a correct answer and zero for an incorrect one. There was also no negative point for the wrong or unanswered items. All the correct answers, therefore, were added up to a total sum of 25 and 42 as there were respectively 25 items in the reading test and 42 items in the spelling test.

\section{Data analysis}

A set of descriptive and inferential statistics were used to answer the two research questions in this study. With regard to descriptive statistical procedures, mean and percentage analysis on the data collected from the reading and spelling tests were conducted. Concerning the inferential statistics, for the data in which no violation of the assumptions of normality was found, independent samples t-test was calculated. However, for the scores in which assumptions of normality were violated, Mann-Whitney $U$ Test which is the non-parametric alternative to the independent-samples t-test was used to interpret the participants' answers to the items in reading and spelling tests. The mean scores of students in responding to items in the reading and spelling tests administered to the learners in each group are presented in Table 1.

\section{Table 1}

Descriptive statistics of the experimental and control groups on spelling and reading tests

\begin{tabular}{|c|c|c|c|c|c|c|}
\hline & & $\mathrm{N}$ & Minimum & Maximum & Mean & SD \\
\hline \multirow{2}{*}{ 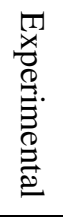 } & Spelling & 50 & 21 & 42 & 35.52 & 4.83 \\
\hline & Reading & 50 & 13 & 24 & 18.44 & 2.87 \\
\hline \multirow{2}{*}{$\begin{array}{l}\stackrel{2}{0} \\
\stackrel{0}{0}\end{array}$} & Spelling & 50 & 11.00 & 37.00 & 23.56 & 7.27 \\
\hline & Reading & 50 & 4.00 & 21.00 & 11.20 & 3.82 \\
\hline
\end{tabular}

Regarding the reading test, the total mean score of children in the Jolly Phonics (JP) group was 18.44 and that of the control group was 11.20. With regard to the spelling test, the total mean score of the participants in the JP group and control group were 35.52 and 23.56 respectively.

Before calculating the required inferential statistical analyses, initial analyses were performed to investigate violation of the assumptions of normality employing Kolmogorov-Smirnov test (see Table 2). 
Table 2

Tests of normality

\begin{tabular}{|c|c|c|c|c|c|}
\hline & & \multicolumn{3}{|c|}{ Experimental } & Control \\
\hline \multirow{3}{*}{ 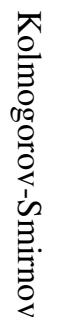 } & & $\underset{\infty}{\stackrel{\mathscr{C}}{E}}$ & $\begin{array}{c}\underset{0}{0} \\
\stackrel{0}{0} \\
\stackrel{0}{0}\end{array}$ & $\underset{\infty}{\stackrel{\mathscr{C}}{\mathscr{C}}}$ & 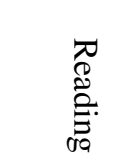 \\
\hline & Statistic & .124 & .122 & .109 & .137 \\
\hline & Sig. & .052 & .060 & .190 & .020 \\
\hline
\end{tabular}

The results of the Kolmogorov-Smirnov test, illustrated in Table 2, showed that the null hypothesis indicating the normality of the scores is rejected (i.e. $p<0.05$ ) as far as the reading scores of control group are concerned. As for other scores, however, no violation of the assumptions of normality was found.

In order to investigate the first hypothesis, due to the violation of assumptions of normality, Mann-Whitney $\mathrm{U}$ Test was used to find out the effect of synthetic multisensory approach to phonics in comparison with traditional approach on young learners' reading skills. The results are presented in Table 3.

Table 3

Mann-Whitney U Test on the mean scores of experimental and control group for the reading test

\begin{tabular}{lccc}
\hline Reading & $\mathrm{N}$ & Mean Rank & Sum of Ranks \\
\hline Experimental & 50 & 71.98 & 3599.00 \\
Control & 50 & 29.02 & 1451.00 \\
Total & 100 & & \\
\hline Mann-Whitney U & \multicolumn{3}{|}{176.000} \\
Z & \multicolumn{4}{|}{-7.422} & \\
Asymp. Sig. (2-tailed) & & .000 & \\
\hline
\end{tabular}

The results of the Mann-Whitney Test in Table 2 revealed that there was a statistically significant difference between the experimental and control groups regarding their reading test, $\mathrm{z}=-7.42, p<0.05$. As shown in the Table, the reading test mean scores for the experimental group $(M=71.98)$ were greater than the mean scores of the reading test in the control group $(M=29.02)$.Thus, the first null hypothesis, stating that synthetic multisensory approach to phonics in comparison with traditional approach does not have any significant effect on young Iranian EFL learners' reading skills is rejected.

In order to examine hypothesis 2, Independent samples t-test was run. Preliminary analyses were performed to ensure that the assumptions of normality were not violated (see Table 2). The results of the t-test are presented in Table 4.

\section{Table 4}

Independent samples $t$-test for the spelling test of experimental and control groups

\begin{tabular}{lcccccc}
\hline & \multicolumn{3}{c}{$\begin{array}{c}\text { Levene's Test for } \\
\text { Equality of Variances }\end{array}$} & \multicolumn{3}{c}{ t-test for Equality of Means } \\
\cline { 2 - 7 } & $\mathrm{F}$ & Sig. & $\mathrm{t}$ & df & Sig. (2-tailed) & Mean Difference \\
\hline $\begin{array}{l}\text { Equal variances not } \\
\text { assumed }\end{array}$ & 13.135 & .000 & 9.679 & 85.171 & .000 & 11.96000 \\
\hline
\end{tabular}

The results illustrated in Table 5 shows that there is a statistically significant difference between the 
Farokhbakht, L., \& Nejadansari, D.

experimental and control group concerning their spelling scores, $t(85.171)=9.67$. As the Table illustrates, the spelling test mean scores for the experimental group were higher than the spelling test mean scores for the control group $(M D=11.96)$. Analysis of the obtained results indicated that the experimental group gained higher scores on the spelling test in comparison to the control group. Consequently, hypothesis 2 is rejected.

\section{Discussion and conclusion}

The primary purpose of this research study was to inquire into possible effects of adopting a synthetic multisensory phonics approach (i.e. Jolly Phonics) in teaching early literacy skills on children's literacy attainments in early stages. The descriptive along with interferential statistics showed that the experimental group who had received the JP intervention performed significantly better on reading and spelling tests than the control group who were taught literacy through ordinary methods organized over rote traditional phonics. These findings were in accordance with similar trials which were run in English-speaking countries such as Canada (Sumbler \& Willows, 1996), England (Grant, 1998) and Scotland (Johnston \& Watson, 2005) and their results revealed that the JP groups showed substantial advantages on every measure of literacy including word reading, spelling and even reading comprehension. Our results were also in agreement with those of the studies conducted in ESL contexts or on ESL students. Stuart (1999) carried out a study with 112 five-year-old pupils, 96 of whom were ESL learners and found that the JP children were significantly ahead of the control ones on standardized tests of reading and spelling. Similarly, the findings of the study by Ekpo et al. (2007) on 168 primary-one Nigerian pupils showed that the experimental i.e. JP group obtained from 3-29 months reading age in the Burt Reading Test at the end of the 36-week treatment. Moreover, in line with Dixon et al. (2011), who studied the effects of JP intervention on 500 children's literacy skills of low-income areas in India and were turned up with significant improvements of the experimental students in reading and spelling tests, the present study came up with similar results. Furthermore, Eshiet (2012) looked into the possible effects of Jolly phonics on the improvements of Nigerian pupils' reading skills. The findings showed extremely positive effects on children's reading achievement. Our findings also accorded with Shepherd (2013) who investigated the effects of JP programme on increasing basic literacy skills of Nigerian primary school pupils. The results of her study indicated that after the 8-month treatment, the children in JP groups performed at a much higher level on the assessments than those who received their normal literacy instruction.

The findings of our study were also in agreement with those of the research studies which examined the effects of other multisensory approaches to literacy than JP on both students with special needs such as low-ability or hearing impaired children and English language learners (ELL). For instance, Schneider and Evers (2009) conducted a study in which they made use of multiple multisensory structured language (MSL) teaching strategies with several ESL students. They concluded that MSL instruction showed promising results for struggling ELLs.

In addition, our outcomes were highly in accordance with the findings reached by the empirical studies which employed other synthetic phonics methods rather than Jolly Phonics in both L1 and ESL/EFL contexts. Shue (2008) explored the effects of explicit i.e. synthetic phonics instruction on the phonological awareness, blending and segmenting skills of 34 EFL second-graders in Taiwan. The findings revealed that after one semester of the intervention, the subjects had improved in phonological awareness, VC blending and phoneme-segmentation tasks. In a similar way, Kodae and Laohawiriyanon (2011) probed the efficacy of intensive synthetic phonics teaching on reading and spelling attainments of EFL Thai 5-graders. After the 8-week treatment, the results suggested that both middle and low-achievers had greatly benefited from the programme.

However, our findings were not in line with Wyse and Style (2007), Goswami (2007), and Wyse and Goswami (2008) who asserted that due to the phonological complexity and inconsistency of English writing system, it is highly unlikely that one method of teaching phonics such as synthetic phonics will be superior to another and will produce outstanding results in literacy acquisition of children. Nevertheless, unlike what was pointed out in the abovementioned studies, the synthetic phonics method of JP led to children's significant gains 
in both word reading and spelling in our study. The possible explanation for the variations in results of the present study and those of the others is just the same as what Goswami $(2005,2007)$ highlights that some English words like 'yacht' cannot be easily recoded by synthetic phonics and must be learnt as distinct or holistic patterns, although the Jolly Phonics programme applies a synthetic phonics approach but it also teaches the 'tricky words' which have irregular spellings separately. As a result, the learning of sight words i.e. the irregularly spelt words which cannot be decoded by blending and segmenting skills are also covered in the JP method. Besides, in addition to the short vowels, the diagraphs which are most of the time problematic for children and are usually overlooked in the traditional approaches are taught in the JP instruction. Likewise, after pinpointing the irregular spelling of English as the main source of children's failure in literacy learning, Jolly (2014) presents the synthetic phonics as the key to successful teaching of literacy learning as following:

Nowadays the teaching of digraphs is seen as essential, as is the teaching of the sound of each letter, rather than just its name. This is key to synthetic phonics teaching. Such teaching does seem to be having a profound effect on illiteracy levels. However it is known that such teaching lifts all children, whatever their social background, and whether English is their first language, with boys doing as well as girls. It is common now for teachers to find they have no children at the end of their first year at school who have a reading age below their actual age ("The Difficulty of English", para. 10).

He further explains that despite not being able to assure that synthetic phonics can compensate for all the inconsistencies in the English writing system and overcome all the difficulties in literacy learning, it can however reduce the number of struggling learners: "It will never overcome the illogical legacy of English spelling, but it does mean that we can expect far fewer children to fail" ("The Difficulty of English", para. 11).

In addition, as Lloyd (2012) puts forward, when you memorize a word rather than blend it (as is usual in whole words methods) it goes the wrong way. In other words, a memorized word goes to the right hemisphere of the brain which has a limited space. The maximum that a human brain can manage to store and memorize is about 2500 words. If you use the first letters as a helping sign, it goes to about 5000 words that is equal to the reading age of nine which is not enough for the educational success of children. On the other hand, if you blend a word for several times, it goes to the left hemisphere which is the place good readers use for decoding and storage. That is when you can memorize well and have this automatic recall for millions of words and this happens because the word is processed rather than memorized.

According to Lloyd (2012), the results of a whole word experiment revealed that after a synthetic phonics intervention, the left hemisphere of students grew and their right hemisphere diminished. So, if you use the left hemisphere, it will expand. Synthetic phonics teaches the alphabetic code from the beginning and applies it to reading and writing. It starts simply with a few letter sounds and gradually builds up to the more complex understanding of the alphabetic code. She further pinpoints that the Jolly Phonics programme leads to more successful literacy learning of children by applying a combination of synthetic and multisensory approaches to phonics. The blending and segmenting (like holding up a finger for each sound) activities, the letter sounds stories and songs, doing the actions when practising the letter sounds, air writing, and etc. Keep children on task and engaged in the process of learning.

To sum up, the findings of the present study advocated that the synthetic multisensory method of Jolly Phonics contributed to higher reading and spelling abilities of students in early stages of learning English literacy. Undoubtedly, the reason for achieving these results is that the students in the control group were taught English literacy through the rote traditional phonics, which lacks any form of motivation for children as the knowledge acquired through rote learning cannot be easily applicable to new (unseen) words. However, the learners in the experimental group learnt literacy skills via Jolly Phonics which results in systematic literacy learning by presenting a synthetic multisensory child-centred approach in teaching the key skills for reading and writing. As Bowey (2006) pinpoints the synthetic phonics method employed in JP programme introduces the letter-sound 
Farokhbakht, L., \& Nejadansari, D.

correspondences in the most fruitful way which provides the children with the key to unlock the door. Learners will figure out the rules and do the rest by themselves. Jolly (2012) also advocates the multisensory approach adopted in Jolly Phonics stating that:

Young children learn particularly quickly when there is a physical activity involved. By doing an action for each letter sound, the children use movement, sight, hearing, and speech to help them remember. This multisensory approach is a very effective way of teaching, as well as being fun for the children (p. 7).

Hence, it can be concluded that as it was referred to by Jolly (2012), the 'fun element' included in this method brought out a new interest in learning literacy for the young learners in this study. Ekpo et al. (2007) also stress that to achieve suitable literacy teaching, well prepared materials and fun games must be incorporated into the teaching programme. In JP programme, children learn better through play and fun carefully-developed games, materials and activities.

\subsection{Pedagogical implications}

The results of this study may add to the inadequate body of research conducted on EFL young learners' literacy attainments. Given the difficulties and complexities of learning to read and write in English which are mostly the outcome of the opaque orthography of this language, the findings might be helpful for all young beginners of English who have turned desperate by the dull and rote phonics methods for learning literacy skills and are therefore looking for ways to overcome the difficulties they encounter with forming and writing letters and blending the sounds together to read and write new words, especially the tricky words which have irregular spellings. Furthermore, the results may be useful for the teachers and even parents of the young learners who are dealing with the first steps of learning literacy in English. The findings can also be beneficial for the language institutes and schools to enhance their students' satisfaction by offering a fun and motivating method for teaching English literacy skills to the children. Teacher trainers and curriculum, material and syllabus designers in both language institutes and government's Ministry of Education may also benefit from the results. Being aware of the key required skills for literacy learning (the most important of which are blending and segmenting) which are taught in Jolly Phonics and the fun and motivating characteristics offered by this method, the curriculum and syllabus designers would better abandon the traditional methods of teaching literacy which are mostly based on memorizations and forceful drills, and instead incorporate the intriguing synthetic multisensory-based Jolly Phonics programme into the curriculum of schools and language institutes.

All in all, this study provides evidence that the synthetic multisensory method of Jolly Phonics programme can be successfully implemented in EFL classrooms for teaching literacy to young beginners and is at least effective in the earliest stages of literacy learning regardless of the fact that the permanence of its effects needs to be further investigated.

\section{References}

Anderson, L. (2004). A taxonomy for learning, teaching and assessing. London: Longman.

Bowey, J. A. (2006). Need for systematic synthetic phonics teaching within the early reading curriculum. The Australian Psychological Society, 41(2), 79-84. http://dx.doi.org/10.1080/00050060600610334

Bradford, J. (2008). Using multisensory teaching methods. Retrieved from http://www.dyslexia-parent.com/mag30.html

Burkard,T. (1999). The end of illiteracy? The Holy Grail of Clackmannanshire. London: Chameleon Press.

Cameron, L. (2001). Teaching languages to young learners. UK: Cambridge University Press. http://dx.doi.org/10.1017/CBO9780511733109

Chall, J. (1983). Learning to read: The Great Debate. New York: McGraw-Hill.

Dixon, P., Schagen, I., \& Seedhouse , P. ( 2011). The impact of an intervention on children's reading and spelling 
Effect of using synthetic multisensory phonics in teaching literacy on EFL young learners' literacy learning

ability in low-income schools in India. School Effectiveness and School Improvement, 22(4), 461-482. http://dx.doi.org/10.1080/09243453.2011.625125

Donnell, W. (2007). The effects of multisensory vowel instruction during word study for third-grade students. Reading Research Quarterly, 42(4), 468-471. http://dx.doi.org/10.1598/RRQ.42.4.2

Ekpo, C. M., Udosen, A. E., Afangideh, M. E., Ekukinam, T. U., \& Ikorok, M. M. (2007). Jolly phonics strategy and the ESL pupils' reading development: a preliminary study. Paper presented at 1 st Mid Term Conference held at the University of Ibadan, Ibadan, Oyo State.

Eshiet, O. I. (2012). Synthetic phonics as a tool for improving the reading skills of Nigerian pupils. ARECLS, 9, 141-162.

Gaskins, I. W., Downer, M. A., Anderson, R.C., Cunningham, P. M., Gaskins, R. W., \& Schommer, M. (1988). A metacognitive approach to phonics: Using what you know to decode what you don't know. Remedial and Special Education, 9(1), 36-41. http://dx.doi.org/10.1177/074193258800900107

Goswami, U. (2007). Learning to read across languages: The role of phonics and synthetic phonics. In Goouch, K., \& Lambirth, A. (EDs.) (2007). Understanding phonics and teaching of reading: Critical perspective (pp. 124-143). England: Open University Press.

Goswami, U., \& Bryant, E. (1990). Phonological skill and learning to read. Hove, UK: Erlbaum.

Gregory, E. (2008). Learning to read in a new language. London: Saga Publications Ltd.

Gunning, T. G. (2009). Creating literacy instruction for all students. Boston, MA: Allyn \& Bacon.

Harrison, C. (2004). Understanding reading development. London: Sage Publication.

Johnston, R. S., \& Watson, J. E. (2005). The effects of synthetic phonics teaching on reading and spelling attainment. Unpublished manuscript, Department of Psychology, University of Hull, Kingston upon Hull, England.

Jolly, C. (2012). Jolly phonics extra. Teacher's book. Malaysia: Jolly Learning Ltd.

Jolly, C. (2014, October 28). The difficulty of English [Web log post]. Retrieved from http://jollylearning.co.uk/2014/10/28/difficulty-english/

Kodae, H., \& Laohawiriyanon, C. (2011). Effects of intensive phonics instruction on reading and spelling attainment of Thai grade 5 learners with reading difficulties. Paper presented at the 3rd International Conference on Humanities and Social Sciences, Department of Languages and Linguistics, Faculty of Liberal Arts, Prince of Songkla University, Hat Yai, Sogkhla, Thailand.

Kuo, L. (n.d). Library declaration and deposit agreement. Unpublished doctoral dissertation. The University of Warwick, United Kingdom.

Lloyd, S.. (2012, February 22). Video podcast. Retrieved from http://content-jollyphonicsuk.cpdcollege.com/node/356

Mohler, G. M. (2002). The effect of direct instruction in phonemic awareness, multisensory phonics, and fluency on the basic reading skills of low-ability seventh grade students. Unpublished doctoral dissertation. The University of Nebraska, Nebraska.

Pretorius, E., \& Mampuru, M. (2007). Playing football without a ball: Language, reading and academic performance in a high-poverty school. Journal of Research in Reading, 30(1), 38-58. http://dx.doi.org/10.1111/j.1467-9817.2006.00333.x

Salfer, N. (2006). Implementing a multisensory reading program for kindergarten students in charter school. Unpublished manuscript. Nova University, Florida, United States.

Schemo, D. (2002). Education bill urges new emphasis on phonics as method for teaching reading. New York Times, p. A16.

Schneider, E., \& Evers, T. (2009). Linguistic intervention techniques for at-risk English language learners. Foreign Language Annals, 42(1), 55-76. http://dx.doi.org/10.1111/j.1944-9720.2009.01008.x

Shepherd, S. (2013). Does intensive synthetic phonics instruction improve the literacy skills of primary one children in cross river state? Unpublished masteral thesis. Nigeria University. Nigeria.

Sheu, W. (2008). The effect of explicit phonics instruction on the development of phonological awareness .Unpublished masteral thesis. Institute of English national Taiwan normal university, Taiwan.

Stuart, M. (1999). Getting ready for reading: Early phoneme awareness and phonics teaching improves reading 
Farokhbakht, L., \& Nejadansari, D.

and spelling in inner-city second language learners. British Journal of Educational Psychology, 69, 587- 605. http://dx.doi.org/10.1348/000709999157914

Sumbler, K., \& Willows, D. (1996). Phonological awareness and alphabetic coding instruction within balanced senior kindergartens. Paper presented as part of the symposium Systematic Phonics within a balanced Literacy.

Teaching Literacy with Jolly Phonics. (2014, December). Retrieved from http://jollyleraning.co.uk/overview-about-jolly-phonics

Trezek, B. J., Gampp, T. L., Wang, Y., Paul, P. V., \& Woods, D. G. (2007). Using visual phonics to supplement beginning reading instruction for students who are deaf or hard of hearing. Journal of Deaf Studies and Deaf Education. Available from http://jdsdc.oxfordjournals.org http://dx.doi.org/10.1093/deafed/enm014

Ureno, S. (2012). Using multisensory methods in reading and literacy instruction. Unpublished manuscript, University of La Verne, La Verne, California, USA.

World Bank Gambia EGRA Report. (2008). Early Grade Reading Assessment (EGRA). Results from 1200 Gambian Primary Students Learning to Read in English, Report for the World Bank.

Wyse, D., \& Goswami, U. (2008). Synthetic phonics and the teaching of reading. British Educational Research Journal, 34(6), 691-710. http://dx.doi.org/10.1080/01411920802268912

Wyse, D., \& Styles, M. (2007). Synthetic phonics and the teaching of reading: the debate surrounding England's 'Rose Report'. United Kingdom literacy association publication, 41(1), 35-42.

http://dx.doi.org/10.1111/j.1467-9345.2007.00455.x 